\title{
Catalytic graphitization of three-dimensional wood-derived porous scaffolds
}

\author{
M.T. Johnson and K.T. Faber ${ }^{\text {a) }}$ \\ Department of Materials Science and Engineering, Robert R. McCormick School of Engineering and Applied \\ Science, Northwestern University, Evanston, Illinois 60208-3108
}

(Received 20 September 2010; accepted 25 November 2010)

\begin{abstract}
A catalytic technique to enhance graphite formation in nongraphitizing carbons was adapted to work with three-dimensional wood-derived scaffolds. Unlike many synthetic graphite precursors, wood and other cellulosic carbons remain largely disordered after high temperature pyrolysis. Using a nickel nitrate liquid catalyst and controlled pyrolysis conditions, wood-derived scaffolds were produced showing similar graphitic content to traditional pitch-based graphite while retaining the high-aspect ratio pores of the precursor wood microstructure. Graphite formation was studied as a function of processing time and pyrolysis temperature, and the resulting carbons were analyzed using x-ray diffraction, Raman spectroscopy, x-ray photoelectron spectroscopy, and electron microscopy techniques.
\end{abstract}

\section{INTRODUCTION}

Wood-derived scaffold structures have received recent attention due to the advantageous thermal and structural properties that result from the retention of the naturally optimized open porous microstructure of the precursor wood. ${ }^{1-3}$ While previous efforts have focused primarily on the development and characterization of biomorphic silicon carbide from wood, ${ }^{4-10}$ biomorphic graphitic scaffolds are of particular interest due to the attractiveness of porous graphite for use in thermal management devices. ${ }^{11,12}$ Graphitic scaffolds combine low density, low thermal expansion coefficient, and high thermal conductivity, making them ideal candidates for many thermal management applications. ${ }^{13}$

A common graphite precursor used for the fabrication of commercial porous graphitic scaffolds is petroleum pitch, which, like several other petroleum-based carbons, is graphitizable upon heat treatment to temperatures ranging from 1700 to $3000{ }^{\circ} \mathrm{C} .{ }^{11,14}$ When wood carbon is exposed to a similar graphitization heat treatment, turbostratic carbon is produced. ${ }^{15,16}$ Unlike graphite, where carbon layers have well defined stacking and a regular planar spacing $(3.354 \AA)$, turbostratic carbon is composed of misoriented carbon layers with a distribution of planar spacings greater than that of ideal graphite. ${ }^{17}$ Due to the formation of turbostratic carbon under graphitization heat treatment conditions, wood and other cellulose-based materials are considered to be nongraphitizable or hard carbons. ${ }^{15-18}$

To enhance ordering in nongraphitizable carbons, catalytic treatments have been developed that utilize

\footnotetext{
a) Address all correspondence to this author.

e-mail: k-faber@northwestern.edu

DOI: $10.1557 / \mathrm{jmr} .2010 .88$
}

transition metal elements such as iron, ${ }^{19,20}$ cobalt, ${ }^{19,21}$ nickel, ${ }^{19-21}$ and copper ${ }^{22}$ to promote the formation of graphitic carbon at pyrolysis temperatures as low as $500^{\circ} \mathrm{C} .{ }^{19}$ Using the excess free energy of disordered carbon as a driving force, a carbide phase formed from the catalyst species moves preferentially through the disordered carbon structure, consuming disordered carbon and precipitating graphite crystallites. ${ }^{23}$ While several of these catalyst methods have shown promise in affecting the formation of graphite in nongraphitizable carbons, they have only been evaluated for use on synthetic structures (e.g., thin films on the order of $100 \mathrm{~nm}^{19}$ and aerogels containing catalysts introduced during gel synthesis ${ }^{24}$ ) and powdered cellulosic materials (e.g., sawdust ${ }^{20}$ ). Due to the complex natural microstructure of wood precursors, and the inability to incorporate catalyst species during scaffold growth, new methods are necessary to obtain graphitic structures that retain the unique porous geometries of the natural precursor materials.

For this work, a nickel-based catalytic processing technique is applied to two wood precursors. The resulting carbons are evaluated to determine microstructural characteristics as well as the extent of graphitization. Wood species, catalyst exposure time, and pyrolysis temperature are evaluated to determine their effects on the graphitization of three-dimensional natural wood precursors.

\section{EXPERIMENTAL METHODS}

\section{A. Processing of graphitic scaffolds}

Wood-derived graphitic scaffolds were produced from two species: red oak (Quercus rubra) and beech (Fagus sylvatica). Samples were first cut into cubes measuring $2 \mathrm{~cm}$ per side, then allowed to dry thoroughly in an oven 
maintained at $100{ }^{\circ} \mathrm{C}$. A $4.25 \mathrm{M}$ catalyst solution was prepared using nickel (II) nitrate (Alfa Aesar, Ward Hill, MA) and deionized water. The solution was allowed to mix completely, and then the dried wood samples were added. Air was evacuated using a vacuum chamber to ensure infiltration of the wood pore space. Samples were allowed to soak in solution for a prescribed time, ranging from 4 to $120 \mathrm{~h}$. Following the solution treatment, wood cubes were removed and dried, first for $24 \mathrm{~h}$ in air, followed by 7 days in a vacuum-assisted drying oven maintained at $100{ }^{\circ} \mathrm{C}$. Weight change was monitored as a function of time by comparing pre-exposure and postexposure weights for each specimen.

Nickel processed samples were graphitized in a pyrolysis heat treatment carried out in a nitrogen atmosphere. Cubes were loaded into alumina boats and packed with granular silica to promote even heating. Pyrolysis was carried out at $1000{ }^{\circ} \mathrm{C}$ or $1600{ }^{\circ} \mathrm{C}$ with a soak time of $6 \mathrm{~h}$. A ramp rate of $3{ }^{\circ} \mathrm{C} / \mathrm{min}$ was used for both heating and cooling, and nitrogen flow was maintained at $\sim 1 \mathrm{sLpm}$. To demonstrate the removal of catalyst postpyrolysis, selected samples were stirred in a $37 \% \mathrm{HCl}$ solution for $2 \mathrm{~h}$ to reform a soluble $\mathrm{Ni}$ salt that was then rinsed with deionized water overnight prior to analysis. Additional untreated samples of each species were pyrolyzed for comparison.

Analysis of nickel treated graphitized samples was compared against pyrolyzed wood samples that had not undergone a nickel pretreatment as well as a reference standard prepared from a commercially available pitch derived graphite (Poco Graphite, Inc., Decatur, TX). Specific processing parameters for the latter can be found elsewhere ${ }^{28}$; in brief, after foaming with an inert gas and carbonization at $1050{ }^{\circ} \mathrm{C}$, graphitization was carried out $2800{ }^{\circ} \mathrm{C}$

\section{B. Characterization methods}

Scanning electron microscopy (Hitachi S-3400-II SEM, Hitachi, Pleasanton, CA) was used for microstructural evaluation of pyrolyzed scaffolds. Sample porosity and density were determined post-pyrolysis using Archimedes' buoyancy technique. ${ }^{25}$

Samples were evaluated to determine the dependence of catalyst exposure time, pyrolysis temperature, and wood species on the degree of graphitization. Unless otherwise stated, samples were sectioned and characterized along their midplane to assess the efficacy of the process away from the outer surface. X-ray diffraction (XRD) was used to determine the crystallinity of samples while Raman spectroscopy was used to evaluate the type and extent of structural disorder in the carbon product. XRD was performed using a Rigaku ATX-G diffractometer (Rigaku Americas, Woodlands, TX) operating at $50 \mathrm{kV}$ and $240 \mathrm{~mA}$ using $\mathrm{Cu} \mathrm{K} \alpha$ radiation $(1.54 \AA)$ in $\theta-2 \theta$ geometry. An internal silicon standard was used for normalization purposes; however, for clarity these diffraction peaks were subsequently removed. Raman spectra were collected using an Acton TriVista CRS Confocal Raman System (Princeton Instruments, Trenton, NJ) using a Stabilite 2018-RM argon/krypton ion laser (SpectraPhysics, Santa Clara, CA) of wavelength $514.5 \mathrm{~nm}$. For each scaffold examined, five Raman spectra were collected from each of five sample regions, the average of which was then taken to be representative of the entire sample.

Transmission electron microscopy (TEM, JEOL JEM2100 FasTEM, JEOL USA, Inc., Peabody, MA) was performed on a series of Ni-treated samples to determine the effect of graphitization temperature on the morphology of the resulting carbon grains. Samples were prepared by grinding pyrolyzed wood carbons with a mortar and pestle and passing the resulting powder through a 38 $\mu \mathrm{m}$ mesh sieve. The powdered carbon was then dispersed in ethanol and ultrasonicated for $3 \mathrm{~h}$. Following sonication and a 15-min pause to allow larger particulates to settle, the ethanol and powdered carbon solution was deposited via pipette onto a silicon nitride TEM sample holder and allowed to dry. In addition to imaging, selected area electron diffraction (SAED) and electron energy loss spectroscopy (EELS) were used to evaluate the crystallinity and electronic structure of carbon grains.

X-ray photoelectron spectroscopy (XPS, Omicron ESCA Probe, Omicron NanoTechnology GmbH, Taunusstein, Germany) was used to determine $s p^{3} / s p^{2}$ concentration ratios for wood carbons produced under optimized conditions according to XRD and Raman results. After decomposing the $\mathrm{C} 1 s$ photoemission spectra into $s p^{3}$ and $s p^{2}$ contributions, the peak intensities are proportional to atomic densities and a ratio may be calculated. ${ }^{26,27}$ XPS was performed in a UHV chamber with an $\mathrm{Al} \mathrm{K} \alpha$ source. Curve fitting was performed iteratively using the XPSpeak 4.1 software package and $s p^{2} / s p^{3}$ peak positions were determined by reference standards.

\section{RESULTS AND DISCUSSION}

\section{A. Catalyst deposition and microstructural analysis}

By comparing the mass of wood samples before and after catalyst treatment, the deposition of the nickel catalyst may be evaluated as a function of exposure time. Figure 1 depicts the findings for both red oak and beech woods. For approximately the first $24 \mathrm{~h}$ of exposure, a steady increase in weight is evident. Although the magnitude of this change varies slightly between species, the rates of change for both wood precursor types are similar at about $0.25 \mathrm{wt} \% / \mathrm{h}$. After the first $24 \mathrm{~h}$, however, the change in weight remains nearly constant, implying that a maximum of catalyst deposition has been reached and that further exposure would not lead to further nickel deposition. 
Shown in Fig. 2 are SEM micrographs of beech-derived [Figs. 2(a, b)] and red-oak-derived [Figs. 2(c, d)] carbon samples after nickel treatment and $1600{ }^{\circ} \mathrm{C}$ pyrolysis. In both cases, the pore structure of the parent wood type is retained through the pyrolysis process. Both large-diameter

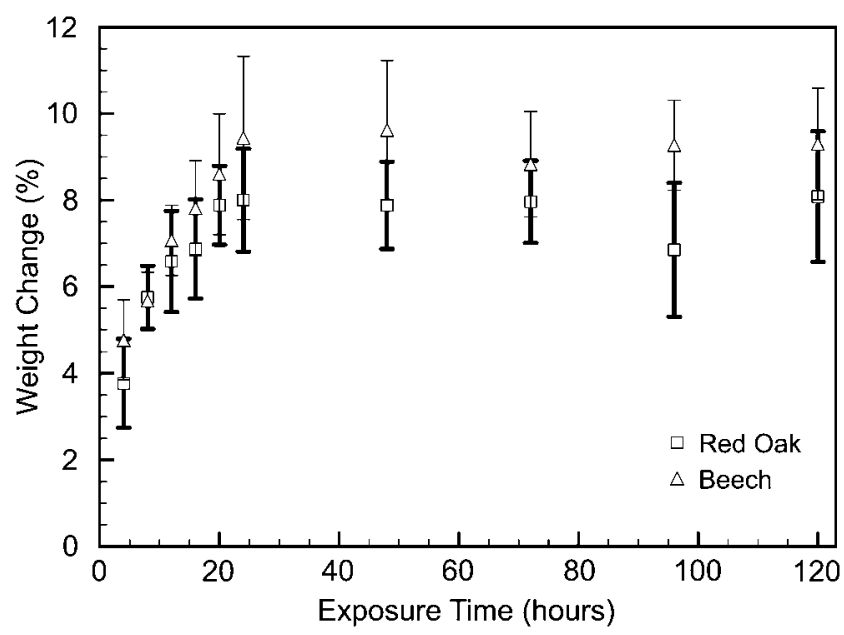

FIG. 1. Sample weight change plotted as a function of exposure time for beech and red oak immersed in a $4.25 \mathrm{M}$ nickel nitrate catalyst solution. Error bars represent $1 \mathrm{SD}$. vessel cells, on the order of $100 \mu \mathrm{m}$, and smaller traechid cells, on the order of $10 \mu \mathrm{m}$, are visible.

Porosities, determined by Archimedes' method for both wood types at each pyrolysis condition, are listed in Table I. Although both wood types produce carbons with similar porosities, as is evident from SEM micrographs, scaffolds produced from different species possess pores of varying size and distribution. Furthermore, porosity volume fractions appear to be independent of pyrolysis temperature. Previous studies using mercury intrusion porosimetry to evaluate porosity and pore size distribution indicate that the pyrolysis process is complete after heat treatment to $\sim 700{ }^{\circ} \mathrm{C}$ and negligible additional changes to microstructure occur. ${ }^{29}$ This observation is in agreement with thermogravimetric analysis (TGA) performed on similar wood species, as reported elsewhere, which show complete decomposition after heating to $\sim 600{ }^{\circ} \mathrm{C} .{ }^{15}$

\section{B. XRD and Raman spectroscopy characterization}

Using XRD and Raman spectroscopy, post-pyrolysis samples were evaluated to determine the nature of carbon crystallinity as well as the extent of remaining structural disorder. Shown in Fig. 3 are XRD profiles and Raman spectra for beech and red oak samples with either no
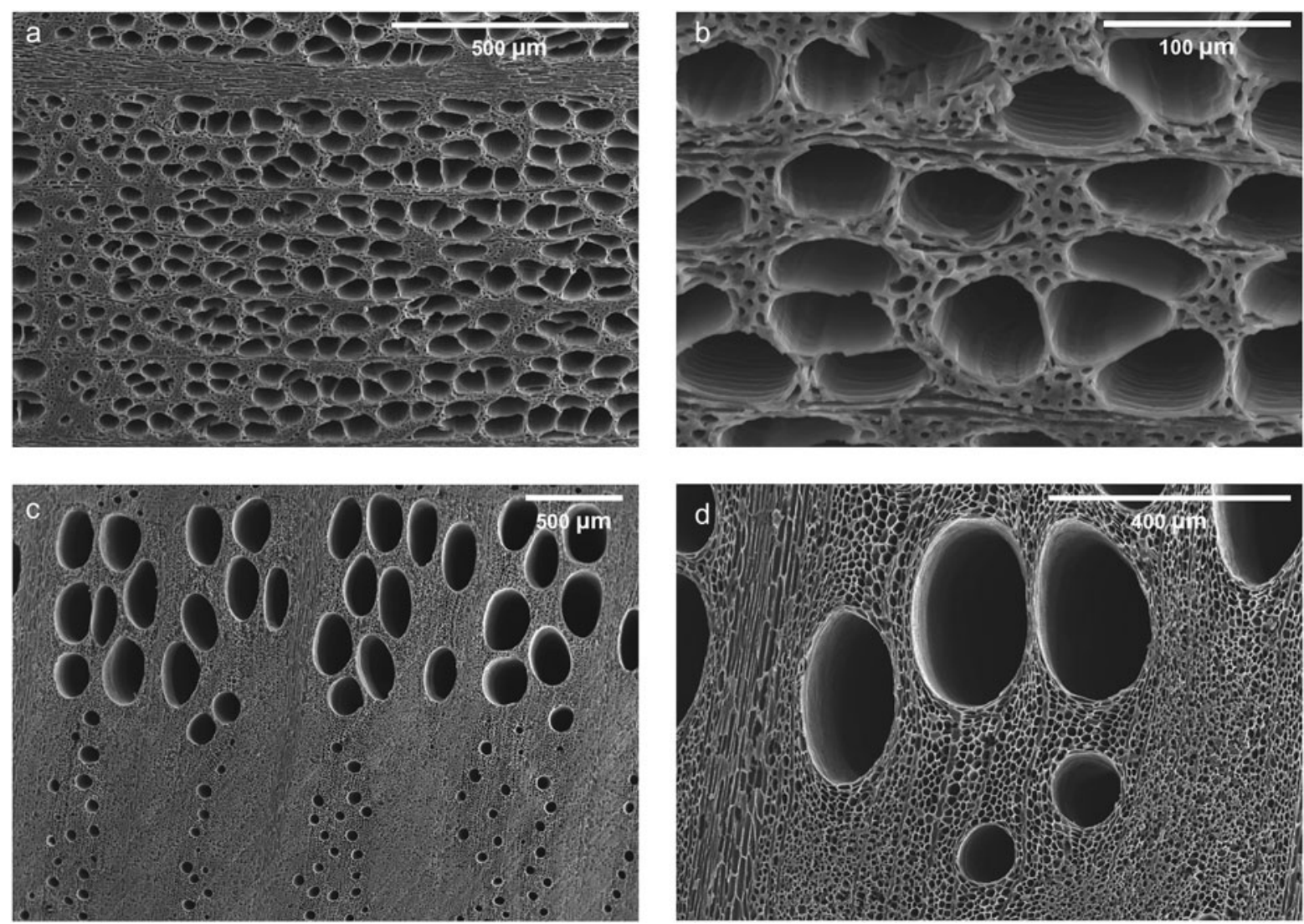

FIG. 2. Representative scanning electron micrographs of (a, b) beech-derived graphite and (c, d) red-oak-derived graphite, pyrolyzed to $1600{ }^{\circ} \mathrm{C}$ after $120 \mathrm{~h}$ of catalyst exposure. 
TABLE I. Porosities, in vol\%, determined from the Archimedes method for beech and red oak samples, treated as specified. Ranges represent \pm 1 SD.

\begin{tabular}{lcccc}
\hline \hline & Untreated wood & $1000{ }^{\circ} \mathrm{C} 120 \mathrm{~h} \mathrm{Ni}$ & $1600{ }^{\circ} \mathrm{C} 120 \mathrm{~h} \mathrm{Ni}$ & $1600{ }^{\circ} \mathrm{C}$ without Ni \\
\hline Beech & $59.28 \pm 0.20$ & $67.51 \pm 0.60$ & $67.96 \pm 0.52$ & $67.91 \pm 1.14$ \\
Red oak & $60.56 \pm 1.05$ & $70.92 \pm 0.98$ & $70.92 \pm 0.71$ & $68.21 \pm 2.06$ \\
\hline \hline
\end{tabular}
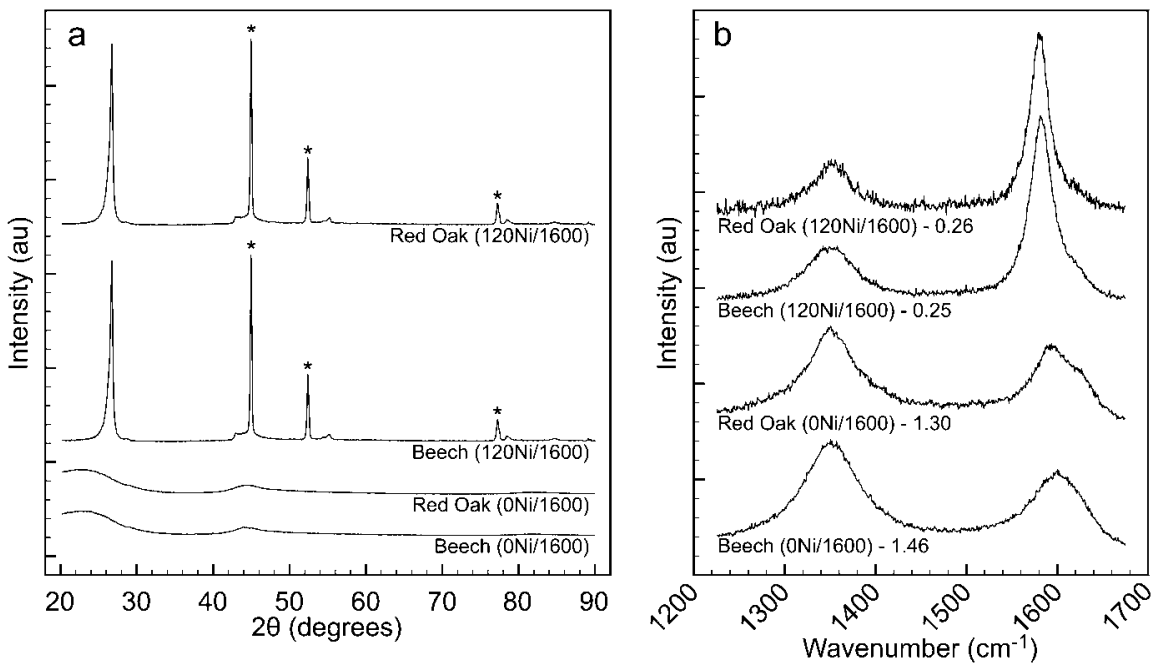

FIG. 3. (a) X-ray diffraction and (b) Raman spectroscopy species comparison for beech and red oak woods after exposure to nickel catalyst for $0 \mathrm{~h}$ $(0 \mathrm{Ni})$ or $120 \mathrm{~h}(120 \mathrm{Ni})$, pyrolyzed to $1600{ }^{\circ} \mathrm{C}$. Nickel diffraction peaks are marked by $(\star)$ and Raman $I_{\mathrm{D}} / I_{\mathrm{G}}$ area ratios are included for reference.

catalyst exposure $(0 \mathrm{Ni})$ or $120 \mathrm{~h}(120 \mathrm{Ni})$ of catalyst exposure, which have been pyrolyzed to $1600{ }^{\circ} \mathrm{C}$. Both nickel-containing samples show graphitization upon heat treatment as evidenced by the strong (002) reflection at $2 \theta=26.6^{\circ}$ observed in the XRD pattern in Fig. 3(a). Here, in contrast to nickel-free samples which show an amorphous diffraction pattern, nickel-containing samples show characteristic graphitic diffraction peaks.

Figure 3(b) again shows a transition from highly disordered carbon in samples prepared without nickel catalyst to graphitic carbon with greater ordering in samples prepared with the catalyst species. Raman spectra of carbon materials are composed of four first-order Raman bands, each arising from different vibratory modes. ${ }^{30}$ In a graphitic material, the most prominent band, the G-band, is located near $1580 \mathrm{~cm}^{-1}$ and represents lattice vibration in an ideal graphitic lattice. With increasing structural imperfection, disorder (D) bands appear. The D1 $\left(1350 \mathrm{~cm}^{-1}\right)$, D2 $\left(1620 \mathrm{~cm}^{-1}\right)$, and D3 $\left(1500 \mathrm{~cm}^{-1}\right)$ bands represent vibrations from graphene layer edges, surfaces, and amorphous regions, respectively. ${ }^{31}$ The band positions, full widths at half maximum, and peak intensity ratios of the prominent $G$ and $D 1$ bands are indicators of the degree of graphitic content. ${ }^{20}$ In Fig. 3(b), samples from both wood species pyrolyzed with nickel catalyst show well-defined graphitic Raman features with smaller disorder contributions when compared to noncatalyzed samples.
When XRD patterns and Raman spectra are compared for beech and red oak woods, similar graphitization behavior is observed in the presence of the nickel catalyst. This result is to be expected since all wood species are composed of the same three carbon-based components-cellulose, hemicellulose, and lignin. ${ }^{32}$ Based upon XRD and Raman data, the pyrolysis and graphitization behavior of these carbon-containing precursors in the presence of nickel catalyst is independent of wood species, affording the ability to tailor scaffold microstructure with wood precursor choice.

To determine graphitization temperature dependency, beech samples were exposed to the catalyst solution for $24 \mathrm{~h}$ then pyrolyzed to 1000 or $1600{ }^{\circ} \mathrm{C}$. The resulting XRD and Raman spectra are summarized in Fig. 4. Although the sample pyrolyzed to $1000{ }^{\circ} \mathrm{C}$ shows the onset of graphitic crystallinity, increasing the heat treatment temperature to $1600{ }^{\circ} \mathrm{C}$ yields diffraction peaks with increased kurtosis, indicative of greater crystalline ordering. Raman data show a similar trend with graphitic (G) contributions increasing with respect to disordered (D1-D3) contributions.

By comparison, Fig. 5 shows diffraction profiles and Raman spectra for three beech wood samples, each graphitized at $1600{ }^{\circ} \mathrm{C}$ for $5 \mathrm{~h}$, but with different durations of nickel treatment. While both nickel-treated samples, 24 and $120 \mathrm{~h}$, show graphitic crystallinity with XRD, differences are observed in Raman spectra. The 24-h sample 

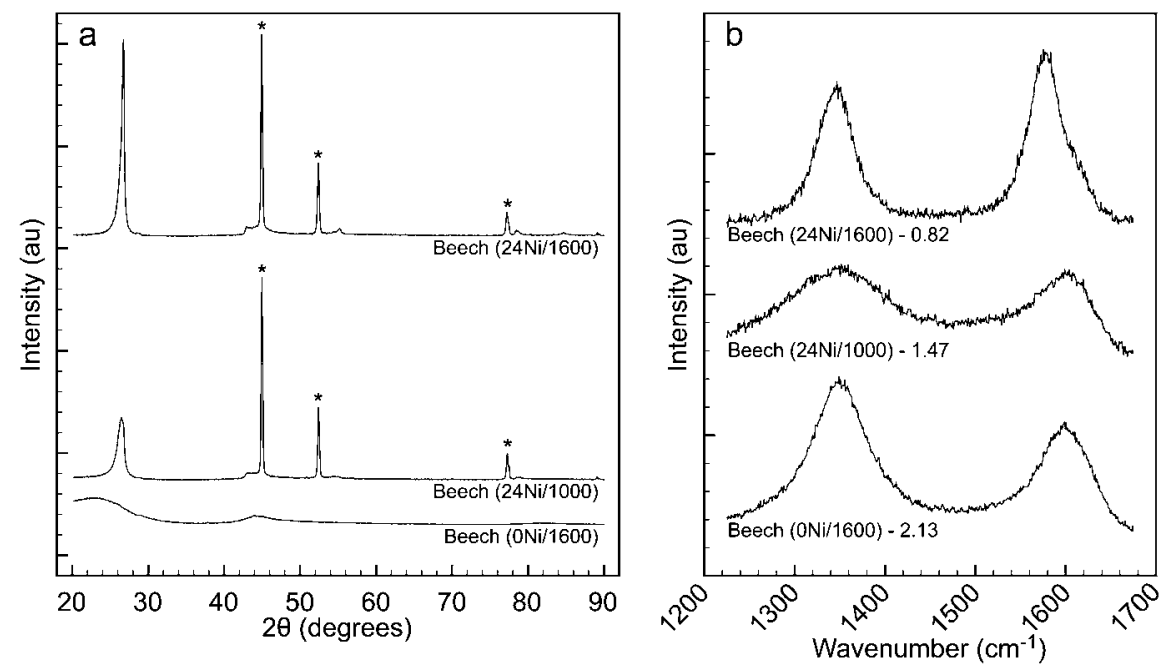

FIG. 4. (a) X-ray diffraction and (b) Raman spectroscopy pyrolysis temperature comparison of three beech samples exposed to nickel catalyst for $0 \mathrm{~h}$ $(0 \mathrm{Ni})$, or $24 \mathrm{~h}(24 \mathrm{Ni})$ and pyrolyzed to either 1000 or $1600^{\circ} \mathrm{C}$. Nickel diffraction peaks are marked by $(\star)$ and Raman $I_{\mathrm{D}} / I_{\mathrm{G}}$ area ratios are included for reference.
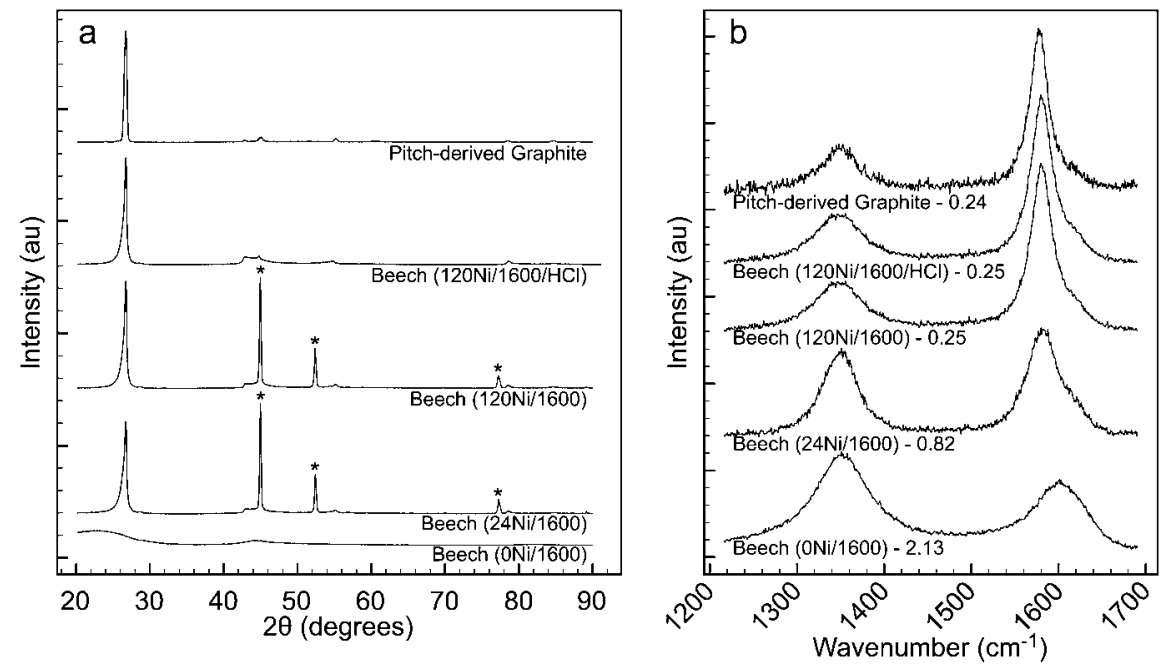

FIG. 5. (a) X-ray diffraction and (b) Raman spectroscopy catalyst exposure time comparison of three beech samples, exposed to nickel catalyst for $0 \mathrm{~h}(0 \mathrm{Ni}), 24 \mathrm{~h}(24 \mathrm{Ni})$, or $120 \mathrm{~h}$ prewash and postwash $(120 \mathrm{Ni}$ and $120 \mathrm{Ni} / \mathrm{HCl})$ and pyrolyzed to $1600{ }^{\circ} \mathrm{C}$. For comparison, a pitch-derived graphite is included. Nickel diffraction peaks are marked by $(\star)$ and Raman $I_{\mathrm{D}} / I_{\mathrm{G}}$ area ratios are included for reference.

shows a moderate G-band contribution; however, the D1 and D2 bands remain relatively strong. With additional exposure time, the 120-h sample shows a dominant Gband with smaller disorder contributions.

Although both nickel-containing samples heat-treated to $1600{ }^{\circ} \mathrm{C}$ show similar XRD results, differences in Raman data imply that the additional catalyst deposition time has produced a graphite with larger disorder-free regions and fewer surface and edge disruptions. Although weight change studies (Fig. 1) indicate that there is no significant difference in deposited catalyst quantity as a function of exposure time, Raman data reveal a difference in graphitization behavior. When taking into account sample microstructure, longer deposition time may allow catalyst infiltration into finer pore spaces that would improve graphitization while having minimal influence on observed weight change.

Also included in Fig. 5 are XRD and Raman data for the pitch-derived graphite standard and beech-derived graphite after nickel removal. According to XRD, the heat treatment graphitization of pitch yields a highly crystalline graphite with negligible turbostratic or amorphous components. However, Raman spectra reveal a small edge disorder contribution (D1, $1350 \mathrm{~cm}^{-1}$ ) resulting from the polycrystalline nature of the graphitized pitch. Overall, the disorder remaining in the structure of the graphitized pitch appears on par with that observed in the wood-derived graphite under optimized catalyst exposure and heat 
treatment conditions. Acid washing successfully removes residual nickel, revealing the graphite (101) diffraction peak, previously concealed by the nickel (111) diffraction peak. The comparison of Raman spectra pre- and postacid-wash shows no change in graphitic disorder during nickel removal.

\section{TEM and EELS analysis}

Shown in Fig. 6 are TEM images and corresponding SAED patterns for a graphite standard material [Fig. 6(a)] as well as three carbon samples prepared from beech woodan untreated sample pyrolyzed to $1600{ }^{\circ} \mathrm{C}$, and two nickel treated samples pyrolyzed to 1000 and $1600{ }^{\circ} \mathrm{C}$ [Figs. 6(b)-6(d), respectively]. Beginning with the standard material, a clear platelike grain structure with a polycrystalline diffraction pattern indicative of graphite is evident. By contrast, the untreated beech sample lacks platelike structure and shows an amorphous diffraction pattern, in agreement with previous amorphous XRD results. With nickel treatment and $1000{ }^{\circ} \mathrm{C}$ pyrolysis, the carbon grains remain nonuniform in shape; however, the onset of crystallization is evident from the emergence of discrete diffraction rings in the SAED pattern. With higher heat-treatment temperature, the resulting carbon takes on a dendritic appearance with relatively large crystal regions as indicated by the SAED pattern. The pyrolysis temperature for this sample, $1600{ }^{\circ} \mathrm{C}$, is in excess of the melting point of nickel, $1455{ }^{\circ} \mathrm{C} .{ }^{33}$ At this elevated pyrolysis temperature, precipitation of graphite from localized areas of liquid phase has allowed for the crystallization of dendrite-like regions, absent from observations of samples pyrolyzed at lower temperatures.

EELS spectra taken of the carbon edges of three materials - a commercial pitch-derived graphite, beech wood pyrolyzed to $1600{ }^{\circ} \mathrm{C}$ without catalyst exposure, and beech wood pyrolyzed to $1600{ }^{\circ} \mathrm{C}$ after $120 \mathrm{~h}$ of catalyst exposure-are shown in Fig. 7. After background correction, the fine edge structure of graphitic samples reveal a contribution from the carbon $\pi^{*}$ orbital near an energy loss of $284 \mathrm{eV}$. This feature, not visible in amorphous carbons, arises due to the excitation of carbon K-shell electrons to an anti-bonding $\pi^{*}$ orbital. ${ }^{34}$ In Fig. 7 , this $\pi^{*}$ contribution is evident in beech wood pyrolyzed with catalyst as well as the pitch-derived graphite but absent from the nongraphitic beech wood without nickel exposure.
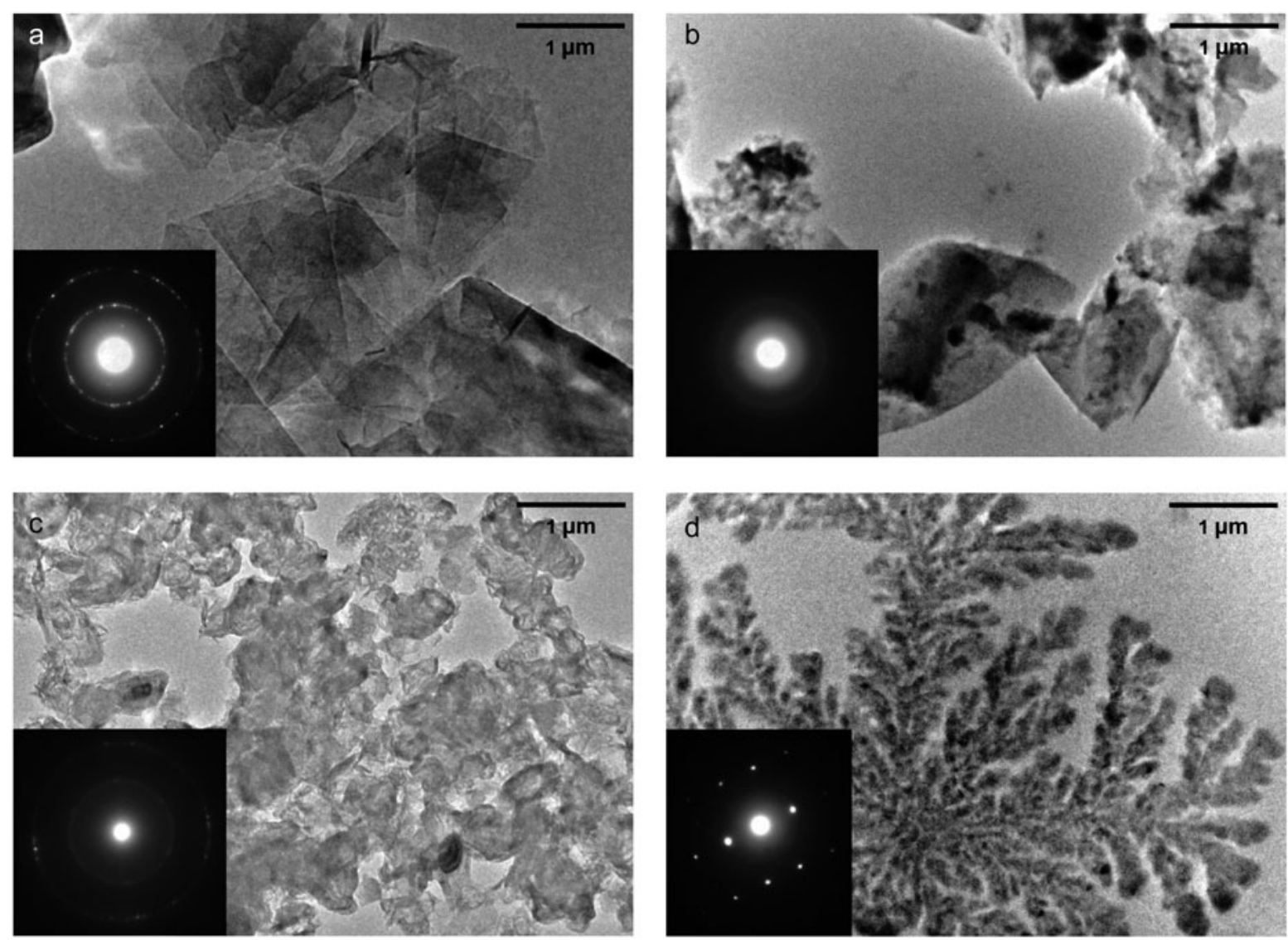

FIG. 6. Transmission electron micrographs and selected area diffraction patterns (inset) of (a) polycrystalline graphite standard; (b) untreated beech wood, pyrolyzed to $1600^{\circ} \mathrm{C}$; (c) beech wood exposed to nickel catalyst for $120 \mathrm{~h}$, pyrolyzed to $1000^{\circ} \mathrm{C}$; and (d) beech wood exposed to nickel catalyst for $120 \mathrm{~h}$, pyrolyzed to $1600^{\circ} \mathrm{C}$. 


\section{XPS analysis}

Shown in Fig. 8 are representative C1s XPS spectra and the resulting curves fit for $s p^{2}$ and $s p^{3}$ carbon for two beech wood samples, both pyrolyzed at $1600{ }^{\circ} \mathrm{C}$, one with nickel treatment and wash and one without treatment, as well as the pitch-derived graphite standard. For fitting purposes,

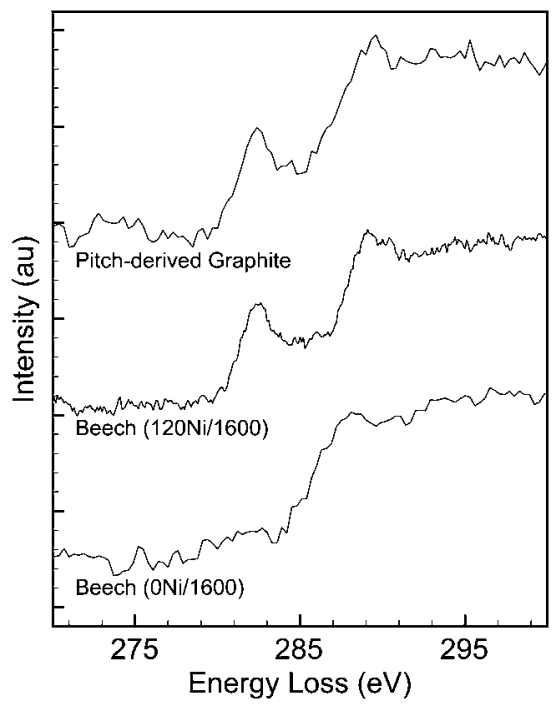

FIG. 7. Near-edge EELS spectra for a pitch-derived graphite standard, beech wood pyrolyzed to $1600{ }^{\circ} \mathrm{C}$ with $120 \mathrm{~h}$ of catalyst exposure $(120 \mathrm{Ni} / 1600)$, and beech wood pyrolyzed to $1600{ }^{\circ} \mathrm{C}$ with no catalyst exposure $(0 \mathrm{Ni} / 1600)$. Spectra are offset for a visual aid, and background signals have been subtracted, leaving only the carbon portion of the spectrum.

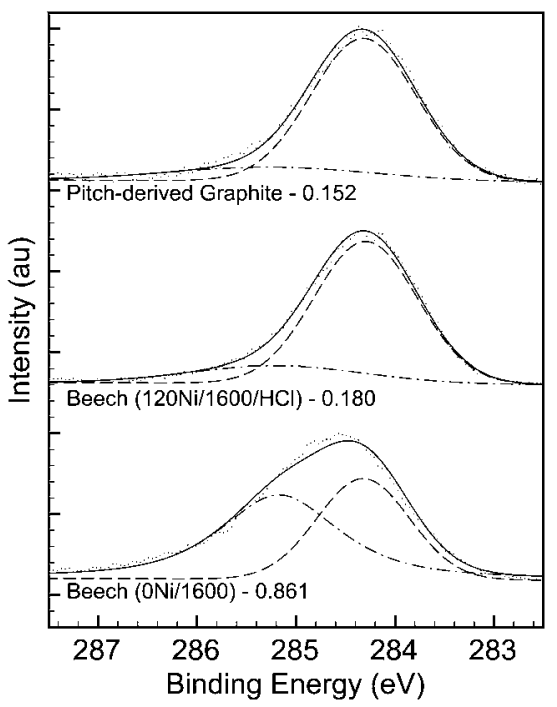

FIG. 8. Carbon $1 s$ XPS spectra for a pitch-derived graphite standard, beech wood pyrolyzed to $1600{ }^{\circ} \mathrm{C}$ with $120 \mathrm{~h}$ of catalyst exposure $(120 \mathrm{Ni} / 1600)$, and beech wood pyrolyzed to $1600{ }^{\circ} \mathrm{C}$ with no catalyst exposure (0Ni/1600). Spectra are offset for a visual aid; hashed lines indicate $s p^{2}$ and $s p^{3}$ contributions with the combined fit shown as a solid line and $s p^{3} / s p^{2}$ ratios are included for reference. reference samples were used to determine the location of $s p^{2}(284.2 \mathrm{eV})$ and $s p 3(285.1 \mathrm{eV})$ spectrum contributions.

As can be seen in the figure, the proportion of $s p^{3}$ to $s p^{2}$ carbon is similar in both the pitch-derived graphite and the beech processed with nickel. In both cases, an $s p^{3}$ contribution remains, likely resulting from the polycrystalline nature of both carbon materials and edge disorder similar to that observed in Raman spectroscopy results. In the beech sample pyrolyzed without nickel, $s p^{2}$ and $s p^{3}$ carbon are observed in similar proportions, as is expected for an amorphous material.

With an X-ray spot size approximately $1 \mathrm{~mm}$ in diameter, XPS effectively probes large sample regions, including both cell walls of both large and small porosity and neighboring solid regions. Comparing the $s p^{3} / s p^{2}$ ratios for each carbon shows a similar degree of graphitization in both the pitch-derived carbon and wood pyrolyzed with nickel catalyst.

By combining XPS with previously described XRD, Raman, and TEM results, the structure of catalytically graphitized wood carbon may be accurately determined. Using XRD alone, the effect of nickel catalysis appears solely dependent on the kinetics of heat treatment. However, Raman spectroscopy reveals a connection between the duration of catalyst exposure and the retention of structural disorder after graphitization, which is not directly evident from other evaluation techniques. EELS and XPS data provide further validation by directly comparing types of carbon bonding. And finally, only TEM imaging and selected area diffraction patterns indicate differences in the morphology of crystalline graphite grown from solid and liquid phases due to heat-treatment temperature.

\section{CONCLUSIONS}

Graphitization using a transition metal catalysis technique has been adapted to work with a three-dimensional, anisotropically porous, natural wood scaffold. Using a liquid catalyst as a carrier to infiltrate wood porosity, graphitic ordering was observed in an otherwise nongraphitizable carbon upon pyrolysis heat treatment and the processing temperature window of graphitization was lowered to a more manageable $1000-1600{ }^{\circ} \mathrm{C}$. X-ray diffraction, Raman spectroscopy, TEM, and XPS methods were used to evaluate the crystallinity and disorder present in resulting carbons as a function of wood precursor, catalyst deposition time, and heat treatment temperature. Although graphitization was determined to be independent of wood precursor, both longer catalyst exposure time and higher graphitization temperature produced a more ordered graphitic carbon. Wood-derived carbon produced after $120 \mathrm{~h}$ of catalyst exposure and $1600^{\circ} \mathrm{C}$ heat treatment showed graphitic ordering comparable to that of the pitchderived graphite reference. 


\section{ACKNOWLEDGMENTS}

This work was funded by the National Science Foundation (DMR-0710630). The SEM, TEM, and Raman spectroscopy work was performed in the EPIC and Keck-II facilities of NUANCE Center at Northwestern University. NUANCE Center is supported by NSFNSEC, NSF-MRSEC, the Keck Foundation, the State of Illinois, and Northwestern University. This work made use of the J.B. Cohen X-ray Diffraction Facility supported by the MRSEC program of the National Science Foundation (DMR-0520513) at the Materials Research Center of Northwestern University.

\section{REFERENCES}

1. P. Greil, T. Lifka, and A. Kaindl: Biomorphic cellular silicon carbide ceramics from wood: I. Processing and microstructure. J. Eur. Ceram. Soc. 18(14), 1961 (1998).

2. P. Greil: Biomorphous ceramics from lignocellulosics. J. Eur. Ceram. Soc. 21(2), 105 (2001).

3. V.S. Kaul, K.T. Faber, R. Sepúlveda, A.R. de Arellano López, and J. Martínez-Fernández: Precursor selection and its role in the mechanical properties of porous $\mathrm{SiC}$ derived from wood. Mater. Sci. Eng., A 428(1-2), 225 (2006).

4. K.E. Pappacena, K.T. Faber, H. Wang, and W.D. Porter: Thermal conductivity of porous silicon carbide derived from wood precursors. J. Am. Ceram. Soc. 90(9), 2855 (2007).

5. P. Greil, T. Lifka, and A. Kaindl: Biomorphic cellular silicon carbide ceramics from wood: II. Mechanical properties. J. Eur. Ceram. Soc. 18(14), 1975 (1998).

6. H. Sieber, C. Hoffmann, A. Kaindl, and P. Greil: Biomorphic cellular ceramics. Adv. Eng. Mater. 2(3), 105 (2000).

7. F.M. Varela-Feria, J. Martínez-Fernández, A.R. de Arellano-López, and M. Singh: Low density biomorphic silicon carbide: Microstructure and mechanical properties. J. Eur. Ceram. Soc. 22(14-15), 2719 (2002).

8. J.M. Qian, J.P. Wang, and Z.H. Jin: Preparation of biomorphic SiC ceramic by carbothermal reduction of oak wood charcoal. Mater. Sci. Eng., A 371(1-2), 229 (2004).

9. K.E. Pappacena, M.T. Johnson, S. Xie, and K.T. Faber: Processing of wood-derived copper-silicon carbide composites via electrodeposition. Compos. Sci. Technol. 70(3), 485 (2010).

10. K.E. Pappacena, M.T. Johnson, H. Wang, W.D. Porter, and K.T. Faber: Thermal properties of wood-derived copper-silicon carbide composites fabricated via electrodeposition. Compos. Sci. Technol. 70(3), 478 (2010).

11. J. Klett, R. Hardy, E. Romine, C. Walls, and T. Burchell: Highthermal-conductivity, mesophase-pitch-derived carbon foams: Effect of precursor on structure and properties. Carbon 38(7), 953 (2000).

12. D. Gaies and K.T. Faber: Thermal properties of pitch-derived graphite foam. Carbon 40(7), 1137 (2002).

13. C. Zweben: Advances in composite materials for thermal management in electronic packaging. JOM 50(6), 47 (1998).
14. R.E. Franklin: The structure of graphitic carbons. Acta Crystallogr. 4(5), 235 (1951).

15. C.E. Byrne and D.C. Nagle: Carbonized wood monoliths-Characterization. Carbon 35(2), 267 (1997).

16. H.M. Cheng, H. Endo, T. Okabe, K. Saito, and G.B. Zheng: Graphitization behavior of wood ceramics and bamboo ceramics as determined by x-ray diffraction. J. Porous Mater. 6(3), 233 (1999).

17. A. Oya and H. Marsh: Phenomena of catalytic graphitization. J. Mater. Sci. 17(2), 309 (1982).

18. K. Ishimaru, T. Hata, P. Bronsveld, and Y. Imamura: Microstructural study of carbonized wood after cell wall sectioning. J. Mater Sci. 42(8), 2662 (2007).

19. R. Sinclair, T. Itoh, and R. Chin: In situ TEM studies of metalcarbon reactions. Microsc. Microanal. 8(4), 288 (2002).

20. M. Sevilla, C. Sanchís, T. Valdés-Solís, E. Morallón, and A.B. Fuertes: Synthesis of graphitic carbon nanostructures from sawdust and their application as electrocatalyst supports. J. Phys. Chem. C 111(27), 9749 (2007)

21. F.J. Derbyshire, A.E.B. Presland, and D.L. Trimm: Graphite formation by dissolution-precipitation of carbon in cobalt, nickel and iron. Carbon 13(2), 111 (1975).

22. C. Yokokawa, K. Hosokawa, and Y. Takegami: A kinetic study of catalytic graphitization of hard carbon. Carbon 5(5), 475 (1967).

23. D.B. Fischbach: The Kinetics and Mechanism of Graphitization, edited by P.L. Walker Jr.(Marcel Dekker, Inc., New York, 1971).

24. F.J. Maldonado-Hódar, C. Moreno-Castilla, J. Rivera-Utrilla, Y. Hanzawa, and Y. Yamada: Catalytic graphitization of carbon aerogels by transition metals. Langmuir 16(9), 4367 (2000).

25. ASTM C373: Standard test method for water absorption, bulk density, apparent porosity, and apparent specific gravity of fired whiteware products. (ASTM International, West Conshohocken, Pennsylvania, 2006).

26. J. Díaz, G. Paolicelli, S. Ferrer, and F. Comin: Separation of the $s p^{3}$ and $s p^{2}$ components in the $\mathrm{C} 1 s$ photoemission spectra of amorphous carbon films. Phys. Rev. B 54(11), 8064 (1996)

27. J. Filik, P.W. May, S.R.J. Pearce, R.K. Wild, and K.R. Hallam: XPS and laser Raman analysis of hydrogenated amorphous carbon films. Diamond Relat. Mater. 12, 974 (2003).

28. J. Klett: Process for making carbon foam. U.S. Patent No. 6033506 (2000).

29. K.E. Pappacena, S.P. Gentry, T.E. Wilkes, M.T. Johnson, S. Xie, A. Davis, and K.T. Faber: Effect of pyrolyzation temperature on wood-derived carbon and silicon carbide. J. Eur. Ceram. Soc. 29 (14), 3069 (2009).

30. F. Tunistra and J.L. Koenig: Raman spectrum of graphite. J. Chem. Phys. 53(3), 1126 (1970).

31. A. Sadezky, H. Muckenhuber, H. Grothe, R. Niessner, and U. Pöschl: Raman micro spectroscopy of soot and related carbonaceous materials: Spectral analysis and structural information. Carbon 43(8), 1731 (2005)

32. J.M. Dinwoodie: Wood: Nature's Cellular, Polymeric, FibreComposite (Institute of Metals, London, 1989).

33. W.F. Smith: Structure and Properties of Engineering Alloys, 2nd ed. (McGraw-Hill, New York, 1993).

34. A.A. El-Barbary, S. Trasobares, C.P. Ewels, O. Stephan, A.V. Okotrub, L.G. Bulusheva, C.J. Fall, and M.I. Heggie: Electron spectroscopy of carbon materials: Experiment and theory. J. Phys. Conf. Ser. 26(1), 149 (2006). 